\title{
Chondrogenic Differentiation Processes in Human Bone Marrow Aspirates upon rAAV-Mediated Gene Transfer and Overexpression of the Insulin-Like Growth Factor I
}

\author{
Janina Frisch, PS, Ana Rey-Rico, PhD, Jagadeesh Kumar Venkatesan, PhD, ${ }^{1}$ Gertrud Schmitt, MS, \\ Henning Madry, MD, ${ }^{1,2}$ and Magali Cucchiarini, $\mathrm{PhD}^{1}$
}

Direct therapeutic gene transfer in marrow concentrates is an attractive strategy to conveniently enhance the chondrogenic differentiation processes as a means to improve the healing response of damaged articular cartilage upon reimplantation in sites of injury. In the present study, we evaluated the ability of the clinically adapted recombinant adeno-associated virus (rAAV) vectors to mediate overexpression of the insulin-like growth factor I (IGF-I) in human bone marrow aspirates that may modulate the proliferative, anabolic activities, and chondrogenic differentiation potential in such samples in vitro. The results demonstrate that successful, significant rAAV-mediated IGF-I gene transfer and expression were achieved in transduced aspirates (up to $105.9 \pm 35.1 \mathrm{pg}$ rhIGF-I/mg total proteins) over time (21 days) at very high levels ( $\sim 80 \%$ of cells expressing the candidate IGF-I transgene), leading to increased levels of proliferation, matrix synthesis, and chondrogenic differentiation over time compared with the control (lacZ) condition. Treatment with the candidate IGF-I vector also stimulated the hypertrophic and osteogenic differentiation processes in the aspirates, suggesting that the regulation of IGF-I expression through $\mathrm{rAAV}$ will be a prerequisite for future translation of the approach in vivo. However, these findings show the possible benefits of this vector class to directly modify marrow concentrates as a convenient tool for strategies that aim at improving the repair of articular cartilage lesions.

\section{Introduction}

$\mathbf{I}$ NJURED, ADULT ARTICULAR cartilage like, during trauma or osteoarthritis does not possess an intrinsic ability for full repair ${ }^{1}$ due to the lack of vascularization in this tissue that potentially may provide reparative progenitor cells in sites of cartilage damage. Several therapeutic options are available to treat articular cartilage defects, including autologous chondrocyte implantation and marrow-stimulating techniques, ${ }^{2-5}$ but these procedures generally lead to the production of a fibrocartilaginous repair tissue (type-I collagen) of lesser quality than the natural hyaline cartilage (type-II collagen, proteoglycans) that does not integrate well with the surrounding unaffected cartilage, and cannot withstand mechanical stress. ${ }^{5-7}$

Such issues have been addressed, at least in part, by elaborating progenitor cell-based therapies for cartilage repair by the administration of isolated chondroregenerative cells like bone marrow-derived mesenchymal stem cells (MSCs) $)^{5,8,9}$ or of marrow concentrates containing MSCs among various cell subpopulations (hematopoietic cells, fibroblasts) as a single-step, convenient therapeutic procedure $^{10-12}$ due to the extensive, specific ability of MSCs to undergo competent chondrogenic differentiation in this environment. ${ }^{13-15}$ Nevertheless, even though the clinical outcomes of such trials have been encouraging, complete reconstruction of an original cartilaginous surface in treated patients has not been reported to date, demonstrating the clear need for improved protocols. ${ }^{5}$ In this regard, approaches based on the transfer of sequences coding for chondrogenic and/or chondroreparative factors may offer strong tools to enhance the healing response of the articular cartilage through transplantation of genetically modified isolated or concentrated progenitor cells. ${ }^{16}$ While a broad number of therapeutic candidates have been evaluated to target isolated MSCs (cartilage oligomeric matrix protein, COMP; transforming growth factor beta, TGF- $\beta$; bone morphogenetic proteins, BMPs; insulinlike growth factor I, IGF-I; basic fibroblast growth factor, FGF-2; Indian hedgehog, IHH; human telomerase, hTERT; small interfering RNA (siRNA) against p53; SOX transcription factors; anti-Runx2/Cbfa1 siRNA; zinc-finger protein

\footnotetext{
${ }^{1}$ Center of Experimental Orthopaedics and ${ }^{2}$ Department of Orthopedic Surgery, Saarland University Medical Center, Homburg/Saar, Germany.
} 
145, ZNF145), ${ }^{17-33}$ relatively few information is available on the feasibility of translating the method to marrow concentrates as a less invasive treatment strategy. Most notably, $\mathrm{Pa}-$ scher et al..$^{34}$ and Ivkovic et al. ${ }^{35}$ employed adenoviral gene transfer to transduce marrow aspirates from rabbit and sheep, achieving relatively short-term levels of transgene expression in such samples in vitro (21 days). In marked contrast, we recently provided evidence that recombinant vectors derived from the human nonpathogenic, replication defective adenoassociated virus (AAV) are capable of effectively ( $\sim 90 \%$ transduction efficiency) and persistently (up to 125 days) modify human marrow aspirates without deleterious effects in vitro, ${ }^{36}$ in good agreement with the properties of the vectors (reduced toxicity and immunogenicity, maintenance of recombinant adeno-associated virus (rAAV) sequences as stable, safe episomes) that make them the currently preferred gene delivery system for clinical applications. ${ }^{16}$

In the present study, in light of our recent work showing the benefits of applying an rAAV IGF-I vector to modulate the proliferative, biosynthetic, and chondrogenic activities in isolated human MSCs, ${ }^{20}$ we examined the ability of this vector to deliver and mediate the expression of this mitogenic and proanabolic growth factor in primary human bone marrow aspirates as a potential approach to enhance the chondrogenic differentiation processes in the samples. Our results show for the first time to the best of our knowledge that rAAV-mediated modification of human marrow aspirates to overexpress IGF-I, stimulates the biological and chondrogenic activities of the samples, probably due to the high and durable levels of growth factor production achieved with this vector class. Transduction with rAAVhIGF-I had also an impact on hypertrophic and osteogenic differentiation, showing that regulation of growth factor expression through rAAV will be decisive to further provide modified aspirates in sites of cartilage damage in vivo.

\section{Materials and Methods}

\section{Reagents}

All reagents were purchased at Sigma unless otherwise indicated. The antibodies used for immunohistochemical analyses were as follows: anti-type-II collagen (II-II6B3; NIH Hybridoma Bank, University of Iowa), anti-type-I collagen (COL-1; Abcam), anti-type-X collagen (COL-10; Sigma), anti-IGF-I (AF-291-NA; R\&D Systems), and anti-SOX9 (C20; Santa Cruz Biotechnology). Secondary biotinylated antibodies and the $\mathrm{ABC}$ reagent were from Vector Laboratories (Alexis Deutschland $\mathrm{GmbH}$ ). The dimethylmethylene blue dye was from Serva. Recombinant TGF- $\beta 3$ was from PeproTech. The IGF-I ELISA (hIGF-I Quantikine ELISA) was from R\&D System. The type-II and type-I collagen ELISAs (CUSABIO) and the type-X collagen ELISA (Cloud-Clone Corp.) were obtained at antibodies-online $\mathrm{GmbH}$.

\section{Plasmids and $\mathrm{rAAV}$ vectors}

The parental AAV-2 genomic clone pSSV9 $9^{37,38}$ was used to create all constructs applied in this study. rAAV-lacZ carries the lacZ gene for Escherichia coli $\beta$-galactosidase and rAAVhIGF-I a human insulin-like growth factor I (hIGF-I) cDNA fragment $(536 \mathrm{bp})$, both under the control of the cytomegalovirus immediate-early (CMV-IE) promoter. ${ }^{20,36,39}$ rAAV were packaged as conventional (not self-complementary) vectors using the 293 adenovirus-transformed embryonic kidney cell line. Adenovirus 5 was used to provide helper functions in combination with the pAd8 helper plasmid as previously described. $^{20,39}$ The vectors were purified, dialyzed, and titrated by real-time polymerase chain reaction (PCR), ${ }^{20,39}$ averaging $10^{10}$ transgene copies $/ \mathrm{mL}$.

\section{rAAV-mediated gene transfer}

Bone marrow aspirates $\left(\sim 15 \mathrm{~mL} ; 1.4 \pm 0.4 \times 10^{9}\right.$ cells $\left./ \mathrm{mL}\right)$ were obtained from the distal femurs of patients undergoing total knee arthroplasty ( $n=8$, age $68 \pm 10$ years). All patients provided informed consent before inclusion in the study and all procedures were in accordance with the Helsinki Declaration. The study was approved by the Ethics Committee of the Saarland Physicians Council. The aspirates containing MSCs $^{34-36}$ were aliquoted in standard tissue culture plastic 96-well plates $(100 \mu \mathrm{L}$ of aspirate/well) and immediately transduced with the rAAV vectors by mixing $40 \mu \mathrm{L}$ of vector solution with each aliquot (i.e., $8 \times 10^{5}$ functional recombinant viral particles, $\mathrm{MOI}=10 \pm 3$ ) and then adding $50 \mu \mathrm{L}$ of Dulbecco's modified Eagle's medium (DMEM) for an incubation time of $1.5 \mathrm{~h}$ at $37^{\circ} \mathrm{C}$ under $5 \% \mathrm{CO}_{2}$. A volume of $60 \mu \mathrm{L}$ of chondrogenic medium (4.5 g/L DMEM high glucose, $100 \mathrm{U} /$ $\mathrm{mL}$ penicillin and $100 \mu \mathrm{L} / \mathrm{mL}$ streptomycin, $6.25 \mu \mathrm{g} / \mathrm{mL}$ insulin, $6.25 \mu \mathrm{g} / \mathrm{mL}$ transferrin, $6.25 \mu \mathrm{g} / \mathrm{mL}$ selenious acid, $5.35 \mu \mathrm{g} / \mathrm{mL}$ linoleic acid, $1.25 \mu \mathrm{g} / \mathrm{mL}$ bovine serum albumin, $1 \mathrm{mM}$ sodium pyruvate, $37.5 \mu \mathrm{g} / \mathrm{mL}$ ascorbate 2-phosphate, $10^{-7} \mathrm{M}$ dexamethasone, and $10 \mathrm{ng} / \mathrm{mL}$ TGF- $\beta 3$ ) was then added per aspirate for an incubation at $37^{\circ} \mathrm{C}$ under $5 \% \mathrm{CO}_{2}$ for up to 21 days based on work adapted for cartilage repair ${ }^{20,36}$ with medium change performed once per week for MSC chondrogenesis. $^{34-36}$ To avoid attachment on the bottom of the plates, the aspirates were carefully mixed after each medium change. For osteogenic and adipogenic differentiation, the aspirates were transduced using similar conditions as those described above and then induced either toward osteogenic differentiation using the StemPro Osteogenesis Differentiation Kit or adipogenic differentiation using the StemPro Adipogenesis Differentiation Kit (both from Life Technologies $\mathrm{GmbH}){ }^{20,32}$

\section{Detection of transgene expression}

To assess IGF-I secretion, $30 \mu \mathrm{L}$ of each aspirate supernatant were collected at the denoted time points $24 \mathrm{~h}$ after medium change and centrifuged to remove debris, and IGF-I production was measured by ELISA as previously described. ${ }^{20,39}$ Quantitative measurements were performed on a GENios spectrophotometer/fluorometer (Tecan). Transgene expression was also monitored by immunohistochemical analysis using a specific primary antibody. ${ }^{20,36,39}$

\section{Histological, immunocytochemical, and immunohistochemical analyses}

The aspirates were collected, fixed in $4 \%$ formalin, dehydrated in graded alcohols, embedded in paraffin, and sectioned $(3 \mu \mathrm{m})$. Sections were stained with Hematoxylin and eosin (H\&E) for cellularity, Toluidine blue for matrix proteoglycans, and Alizarin Red for matrix mineralization as previously described. ${ }^{19,20,32,36}$ Immunohistochemistry was performed to monitor the expression 
of IGF-I, type-II, type-I, and type-X collagen, and SOX9 using specific primary antibodies, biotinylated secondary antibodies, and the $\mathrm{ABC}$ method with diaminobenzidine as the chromogen. ${ }^{19,20,32,36}$ To control for secondary immunoglobulins, sections were processed with omission of the primary antibody. Samples were examined under light microscopy (Olympus BX 45; Olympus).

\section{Histomorphometry}

The levels of cells expressing the transgene (\% of cells positive for IGF-I expression-i.e., IGF-I ${ }^{+}$cells - to the total numbers of cells), the cell densities on H\&E-stained sections, the intensities of Toluidine blue and Alizarin Red staining and of type-II, type-I, and type-X collagen, and SOX9 immunostaining, and the densities of cells stained for Toluidine blue were monitored at 3 random standardized sites or with 10 serial histological and immunohistochemical sections for each parameter, test, and replicate condition using the SIS analySIS program (Olympus), Adobe Photoshop (Adobe Systems), and Scion Image (Scion Corporation). ${ }^{19,20,32,36}$ To evaluate IGF-I expression, only cells strongly stained versus (faint) background diamino-benzidine (DAB) signal, that is, in the absence of primary antibody, were considered as IGF-I ${ }^{+}$. Regarding the measurements of the cell densities, H\&E-stained sections from either lacZ- or IGF-I-treated aspirates were analyzed by counting cells per standardized area using a similar magnification $(\times 40)$ for all types of samples to allow for strict comparison. To monitor the staining intensities, $\times 20$ images were first converted to inverted grayscale mode. Background DAB signal was adapted for comparable range of each type of immunostaining before evaluations. The total areas $\left(\mathrm{mm}^{2}\right)$ covered with cells were next measured to identify the average gray value of the defined area. Data are given as mean intensity of staining or immunostaining per $\mathrm{mm}^{2}$ of total cell area. To generate the $\%$ of Toluidine blue-positive cells, the densities of cells stained for Toluidine blue per $\mathrm{mm}^{2}$ of the total cell area were normalized to the cell densities per $\mathrm{mm}^{2}$ of the total cell areas assessed on H\&E-stained sections.

\section{Biochemical assays}

The aspirates were collected and digested with papain. ${ }^{19,20,32}$ A fluorimetric assay using Hoechst 22358 was applied to determine the DNA contents and the proteoglycans were measured by binding to dimethylmethylene blue dye. ${ }^{19,20,32}$ Analysis of the type-II, type-I, and type-X collagen contents were performed by respective ELISAs. ${ }^{19,20,32}$ Total cellular proteins were monitored through protein assay (Pierce Thermo Scientific, Fisher Scientific) and subsequently used to normalize the biochemical data. All measurements were performed on a GENios spectrophotometer/ fluorometer (Tecan). Osteogenically and adipogenically induced aspirates were processed for quantitative estimation of the alkaline phosphatase (ALP) activities and Oil Red O staining, respectively. ${ }^{40-42}$ Determination of ALP activity was performed by mixing $100 \mu \mathrm{L}$ of osteogenically differentiated aspirate with an equal volume of substrate buffer (4 mg/mL 4-nitrophenyl phosphate-pNPP—-mixed 1:1 with 4.8\% 2-amino-2-methyl-1-propanol-2-AMP) and measuring $\mathrm{OD}^{530 \mathrm{~nm}}$ as previously described. ${ }^{40}$ Estimation of Oil Red $\mathrm{O}$ staining was performed by mixing $100 \mu \mathrm{L}$ of adipogenically induced aspirate with $150 \mu \mathrm{L}$ of staining solution (three volumes of Oil Red O $0.3 \%$ in 2-propanol and two volumes $\mathrm{H}_{2} \mathrm{O}$ ) for $15 \mathrm{~min}$ at room temperature followed by dissolution in $100 \%$ 2-propanol and by measuring OD ${ }^{530 \mathrm{~nm}}$. $40-42$

\section{Real-time RT-PCR analyses}

Total cellular RNA was extracted from all the aspirates at the denoted time points using TRIzol reagent (Ambion ${ }^{\circledR}$ Life Technologies) and the RNeasy Protect Mini Kit with an on-column RNase-free DNase treatment (Qiagen) and RNA elution in $30 \mu \mathrm{L}$ RNase-free water. Eight microliters of eluate were applied to perform reverse transcription by using the First Strand cDNA Synthesis Kit for reverse transcriptase-polymerase chain reaction (RT-PCR) (AMV) (Roche Applied Science). Real-time PCR was carried out to amplify $2 \mu \mathrm{L}$ of the cDNA product by using the Brilliant SYBR Green QPCR Master Mix (Stratagene, Agilent Technologies) on an Mx3000P QPCR operator system (Stratagene) as follows: $\left(95^{\circ} \mathrm{C}, 10 \mathrm{~min}\right)$, amplification by 55 cycles (denaturation at $95^{\circ} \mathrm{C}, 30 \mathrm{~s}$; annealing at $55^{\circ} \mathrm{C}, 1 \mathrm{~min}$; extension at $\left.72^{\circ} \mathrm{C}, 30 \mathrm{~s}\right)$, denaturation $\left(95^{\circ} \mathrm{C}, 1 \mathrm{~min}\right)$, and final incubation $\left(55^{\circ} \mathrm{C}, 30 \mathrm{~s}\right)$. All primers were purchased at Invitrogen: SOX9 (chondrogenic marker) (forward 5'ACACACAGCTCACTCGACCTTG-3'; reverse 5'-GGGA ATTCTGGTTGGTCCTCT-3'), type-II collagen (COL2A1) (chondrogenic marker) (forward 5'-GGACTTTTCTCCCC TCTCT-3'; reverse 5'-GACCCGAAGGTCTTACAGGA$3^{\prime}$ ), aggrecan (ACAN) (chondrogenic marker) (forward 5'-GAGATGGAGGGTGAGGTC-3'; reverse 5'-ACGCTGC CTCGGGCTTC-3'), type-I collagen (COL1A1) (osteogenic marker) (forward 5'-ACGTCCTGGTGAAGTTGGTC-3'; reverse $5^{\prime}$-ACCAGGGAAGCCTCTCTCTC-3'), type-X collagen (COL10A1) (marker of hypertrophy) (forward $5^{\prime}$ CCCTCTTGTTAGTGCCAACC-3'; reverse 5'-AGATT CCAGTCCTTGGGTCA-3'), matrix metalloproteinase 13 (MMP13) (marker of terminal differentiation) (forward $5^{\prime}$ AATTTTCACTTTTGGCAATGA-3'; reverse 5'-CAAAT AATTTATGAAAAAGGGATGC-3'), ALP (osteogenic marker) (forward 5'-TGGAGCTTCAGAAGCTCAACACC A-3'; reverse 5'-ATCTCGTTGTCTGAGTACCAGTCC-3'), osteopontin (OP) (osteogenic marker) (forward $5^{\prime}$-ACGC CGACCAAGGAAAACTC-3'; reverse 5'-GTCCATAAAC CACACTATCACCTCG-3'), runt-related transcription factor 2 (RUNX2) (osteogenic marker) (forward 5'-GCAGTT CCCAAGCATTTCAT-3'; reverse 5'-CACTCTGGCTTT GGGAAGAG-3'), $\beta$-catenin (mediator of the Wnt signaling pathway for osteoblast lineage differentiation) (forward $5^{\prime}$ CAAGTGGGTGGTATAGAGG-3'; reverse 5'-GCGGGA CAAAGGGCAAGA-3'), Indian hedgehog (IHH) (hypertrophy-associated marker) (forward 5'-ATGAAGGCAAGA TCGCTCG-3'; reverse 5'-GATAGCCAGCGAGTTCAGG$3^{\prime}$ ), para thyroid hormone-related protein (PTHrP) (antihypertrophic factor) (forward 5'-CGACGACACACGCACT TGAAAC-3'; reverse 5'-CGACGCTCCACTGCTGAACC$3^{\prime}$ ), and glyceraldehyde-3-phosphate dehydrogenase (GAPDH) (housekeeping gene and internal control) (forward $5^{\prime}$ GAAGGTGAAGGTCGGAGTC-3'; reverse 5'-GAAGATGG TGATGGGATTTC-3') (all 150 nM final concentration). ${ }^{19,20,32}$ Water and non-reverse-transcribed mRNA were used as control conditions. To confirm the specificity of the products, melting curve analysis and agarose gel electrophoresis were performed. The threshold cycle $(\mathrm{Ct})$ value for each amplified 

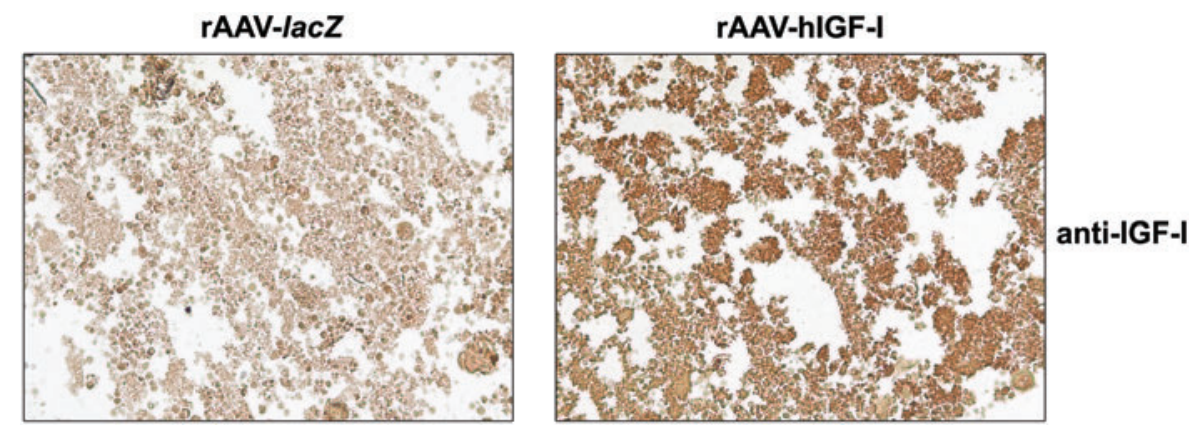

FIG. 1. Detection of insulin-like growth factor I (IGF-I) overexpression in human bone marrow aspirates through recombinant adeno-associated virus (rAAV)-mediated gene transfer. Aspirates were transduced with rAAV-hIGF-I or rAAV-lacZ (40 $\mu \mathrm{L}$ each vector) and kept in chondrogenic medium as described in the Materials and Methods section and processed after 21 days to detect IGF-I expression by immunohistochemical analysis (magnification $\times 20$, representative data). Color images available online at www.liebertpub.com/tea

sample and each gene of interest was measured by using the MxPro QPCR software (Stratagene), and values were normalized to GAPDH expression by using the $2^{-\Delta \Delta C t}$ method as previously described. ${ }^{19,20,32}$

\section{Statistical analyses}

All conditions were performed in triplicates in three independent experiments for each patient and all patients were tested. Data are given as mean \pm standard deviation (SD) of separate experiments. Statistical significance was assessed for any $p$-value of less than 0.05 using the $t$-test and MannWhitney Rank Sum Test, where appropriate.

\section{Results}

\section{Effective IGF-I gene transfer and overexpression} through $r A A V$ in human bone marrow aspirates

Bone marrow aspirates were first transduced with the candidate rAAV-hIGF-I vector compared with the control rAAV-lacZ vector to evaluate the ability of rAAV to mediate direct overexpression of the growth factor in conditions of chondrogenic differentiation. An analysis of IGF-I expression by immunohistochemistry revealed a significantly higher, sustained signal in rAAV-hIGF-I- versus rAAV-lacZ-treated aspirates for up to 21 days, the longest time point evaluated (Fig. 1), while faint staining was seen in any condition when omitting the primary antibody (not shown). These results were confirmed by an analysis of the IGF-I production levels assessed by ELISA, with significantly higher amounts of factor synthesized in the presence of $\mathrm{AAAV}$-hIGF-I relative to rAAV-lacZ $(p \leq 0.042)$ in the presence of similar amounts of total proteins in the samples $(p=1.000)$ (Table 1$)$. The $\%$ of cells expressing IGF-I reached $\sim 80 \%$ with the rAAV IGF-I vector versus $10 \%$ in the control condition (endogenous IGF-I expression) (eight-fold difference, $p \leq 0.001$ ) (Fig. 1).

\section{Activation of the proliferative, biosynthetic activities, and chondrogenic differentiation processes in human bone marrow aspirates following application of $r A A V-h I G F-I$}

Transduction was further performed in chondrogenic conditions to examine the potential effects of IGF-I overexpression through rAAV on the biological activities of human bone marrow aspirates (proliferation, matrix synthesis) compared with control (lacZ) treatment. As we already reported that gene transfer with rAAV does not impair the differentiation potential of bone marrow aspirates, ${ }^{36}$ we did not further include here a condition without vector treatment.

An histological analysis of the transduced aspirates by H\&E staining revealed significantly higher cell densities in the IGFI- versus lacZ-treated samples after 21 days $(0.061 \pm 0.030$ compared with $0.025 \pm 0.011$ cells $/ \mu \mathrm{m}^{2}$ on day 21 , i.e., a 2.4-fold difference, $p \leq 0.001$ ) (Fig. 2A). These results were corroborated by an estimation of the DNA contents in the aspirates (1.2-fold difference, $p=0.007$ ) (Fig. 2B).

Administration of rAAV-hIGF-I also significantly increased the homogeneous intensities of cell-associated Toluidine blue staining (Fig. 3A) and of type-II collagen and SOX9 immunostaining (Fig. 3B, C, respectively) versus rAAV-lacZ $(1132.9 \pm 212.6$ vs. $827.8 \pm 339.6,827.9 \pm 76.5$ vs. $679.3 \pm 49.6$, and $790.5 \pm 22.9$ vs. $685.6 \pm 11.8$ mean intensity $/ \mathrm{mm}^{2}$ total cell area on day 21 for Toluidine blue staining and for type-II collagen and SOX9 immunostaining, i.e., up to a 1.4-fold difference, $p \leq 0.026$ ), with significantly enhanced $\%$ of Toluidine blue-positive cells in the presence of IGF-I $(\sim 100 \%)$ versus lacZ $(14 \% \pm 3 \%$, i.e., about a seven-fold difference, $p \leq 0.001)$ (Fig. 3A). These findings were substantiated by an assessment of the proteoglycan and type-II collagen contents in the aspirates (1.5-fold difference for the proteoglycans, $p=0.022 ; 1.3$-fold difference for type-II collagen, $p=0.176$ ) (Fig. 3A, B). An analysis of the gene expression profiles by real-time RTPCR revealed 19- $(p=0.001), 14-(p=0.040)$, and 56-fold ( $p=$ 0.025 ) higher ACAN, COL2A1, and SOX9 levels, respectively,

Table 1. Detection of IGF-I Expression in rAAV-Transduced Human Bone Marrow Aspirates

\begin{tabular}{lcc}
\hline $\begin{array}{l}\text { Days } \\
\text { posttransduction }\end{array}$ & $r A A V$-lacZ & $r A A V-h I G F-I$ \\
\hline 7 & $61.1 \pm 4.1(11.7 \pm 0.3)$ & $97.0 \pm 0.3^{\mathrm{a}}(10.2 \pm 1.5)$ \\
14 & $36.9 \pm 2.4(13.2 \pm 1.1)$ & $49.2 \pm 7.1^{\mathrm{a}}(12.5 \pm 2.9)$ \\
21 & $85.5 \pm 0.1(12.6 \pm 0.1)$ & $105.9 \pm 35.1^{\mathrm{a}}(13.1 \pm 0.8)$ \\
\hline
\end{tabular}

Values are expressed as mean pg rhIGF-I/mg total proteins \pm SD. Values in the brackets represent the mean total proteins $(\mathrm{mg} / \mathrm{mL}) \pm \mathrm{SD}$.

${ }^{a}$ Statistically significant versus rAAV-lacZ.

IGF-I, insulin-like growth factor I; rAAV, recombinant adenoassociated virus; $\mathrm{SD}$, standard deviation. 
FIG. 2. Proliferative activities in human bone marrow aspirates transduced with rAAV-hIGF-I. Aspirates were transduced and maintained in chondrogenic medium as described in Figure 1 and histologically processed after 21 days to monitor the levels of cell proliferation by (A) Hematoxylin and eosin $(\mathrm{H} \& \mathrm{E})$ staining (magnification $\times 20$, representative data) and (B) biochemical assay (detection of the DNA contents). *Statistically significant compared with rAAV-lacZ. Color images available

A

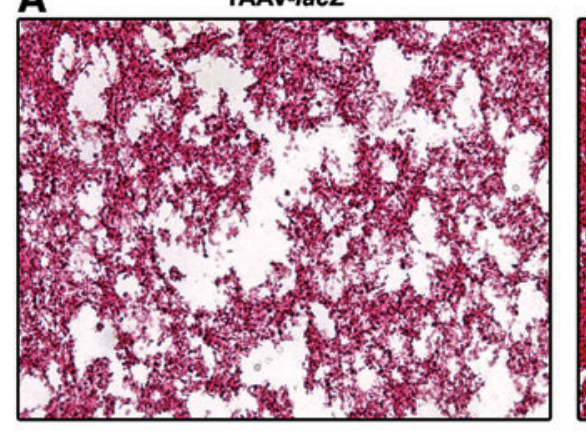

B

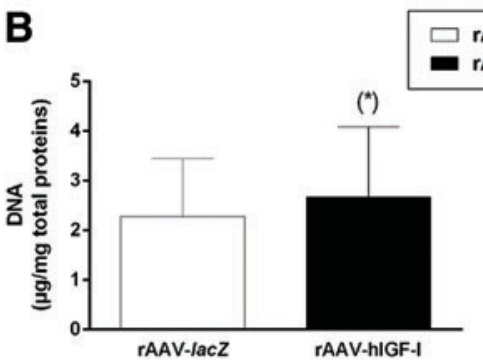

rAAV-hIGF-I

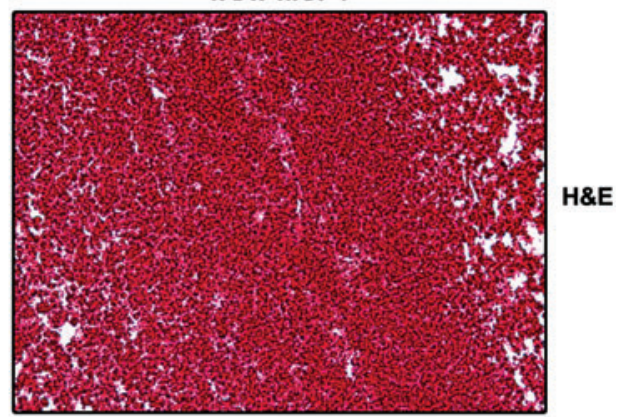

rAAV-lacZ online at www.liebertpub.com/tea

A

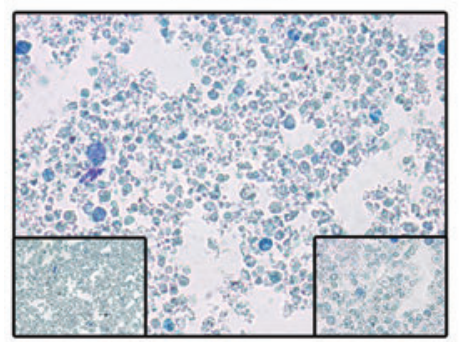

B

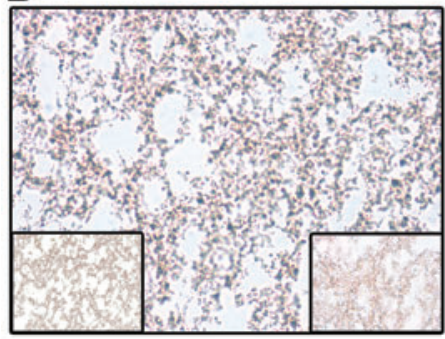

C

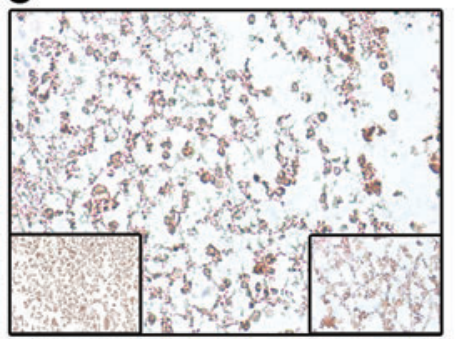

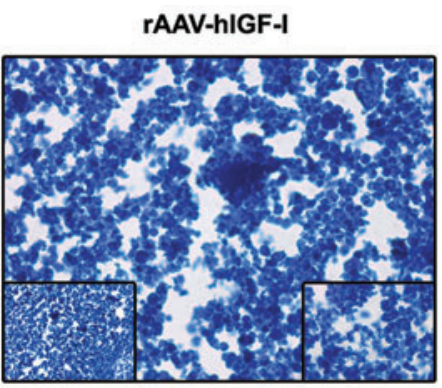

toluidine blue

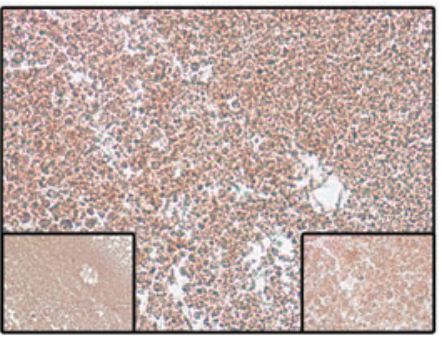

anti-type-II collagen

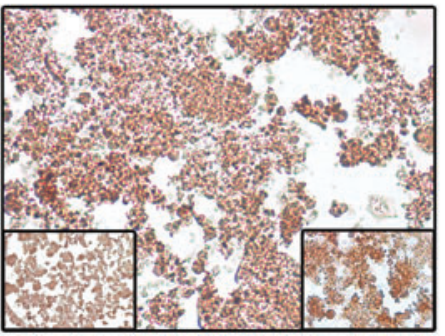

anti-SOX9
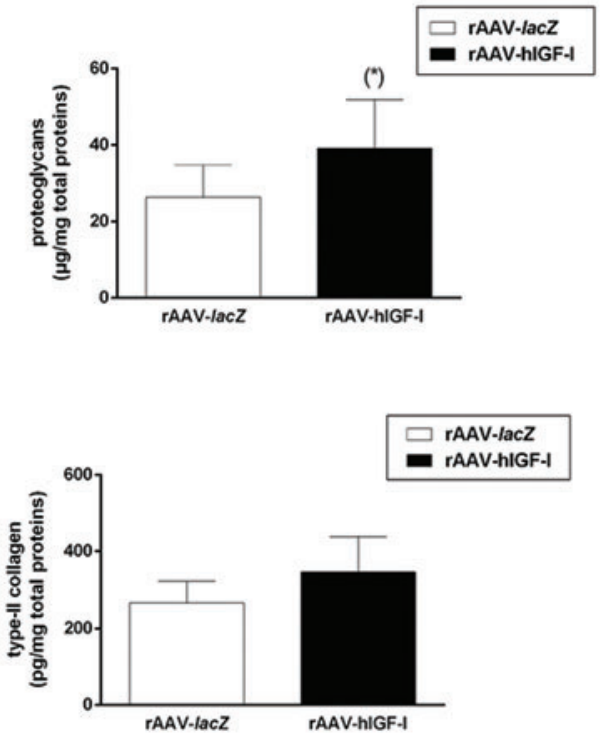

FIG. 3. Biosynthetic activities and chondrogenic differentiation processes in human bone marrow aspirates transduced with rAAV-hIGF-I. Aspirates were transduced and maintained in chondrogenic medium as described in Figure 1 and histologically processed after 21 days to monitor the levels and production of (A) proteoglycans (Toluidine blue staining and estimation of the contents), (B) type-II collagen (immunodetection and estimation of the contents), and (C) SOX9 (immunodetection) (magnification $\times 40$, insets left at magnification $\times 20$, insets right at magnification $\times 100$, representative data). *Statistically significant compared with rAAV-lacZ. Color images available online at www.liebertpub.com/tea 
in the IGF-I- versus lacZ-treated aspirates after 21 days of chondrogenic induction (Fig. 5). An evaluation of the outcomes at day 21 versus day 1 per vector type showed over time increases in chondrogenic marker expression in both types of aspirates (ACAN: 652- and 15,027-fold with lacZ and IGF-I, respectively, i.e., 23-fold more with IGF-I, $p \leq 0.008$; COL2A1: 2791- and 31,590-fold with $l a c Z$ and IGF-I, respectively, i.e., 11-fold more with IGF-I, $p \leq 0.032$; SOX9: 4469- and 250,831fold with $l a c Z$ and IGF-I, respectively, i.e., 56-fold more with IGF-I, $p \leq 0.023$ ) (Fig. 5). Finally, treatment with IGF-I for 21 days enhanced the expression levels of these markers in the aspirates compared with samples treated with $l a c Z$ for 1 day (12,568-, 40,079-, and 252,058-fold for ACAN, COL2A1, and SOX9, respectively, $p \leq 0.011$ ) (Fig. 5).

\section{Hypertrophic and terminal differentiation processes} in human bone marrow aspirates transduced with $r A A V-h I G F-I$

Bone marrow aspirates were next transduced in chondrogenic conditions to examine the possible effects of IGF-I overexpression through rAAV upon hypertrophic and ter- minal differentiation processes compared with control (lacZ) treatment. Notably, application of rAAV-hIGF-I significantly increased the homogeneous intensities of type-I and type-X collagen immunostaining (Fig. 4A, B, respectively) and of Alizarin red staining (Fig. 4C) compared with rAAV-lacZ $(685.6 \pm 95.2$ vs. $542.1 \pm 66.1,655.0 \pm 82.9$ vs. $523.8 \pm 37.3$, and $922.0 \pm 236.4$ vs. $715.2 \pm 337.5$ mean intensity $/ \mathrm{mm}^{2}$ total cell area on day 21 for type-I and type-X collagen immunostaining and for Alizarin red staining, respectively, i.e., up to a 1.3 -fold difference, $p \leq 0.043$ ). These findings were confirmed by an estimation of the type-I and type-X collagen contents in the aspirates (2.1-fold difference for type-I collagen, $p=0.039 ; 1.4$-fold difference for type-X collagen, $p=0.197$ ) (Fig. 4A, B) and by the results of a realtime RT-PCR analysis showing 3.0-fold $(p=0.003)$ and 8.8-fold $(p=0.006)$ higher COL1A1 and COL10A1 levels, respectively, in the IGF-I- versus lacZ-treated aspirates after 21 days of chondrogenic induction (Fig. 5). An evaluation of the outcomes at day 21 versus day 1 per vector type revealed over time increases in the expression of these markers in both types of aspirates (COL1A1: 79- and 271-fold with lacZ and IGF-I, respectively, i.e., 3.4-fold more with IGF-I,
A

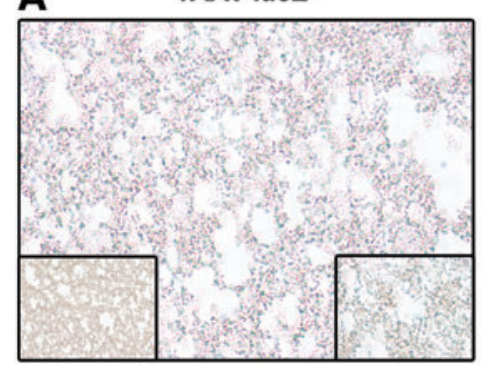

B

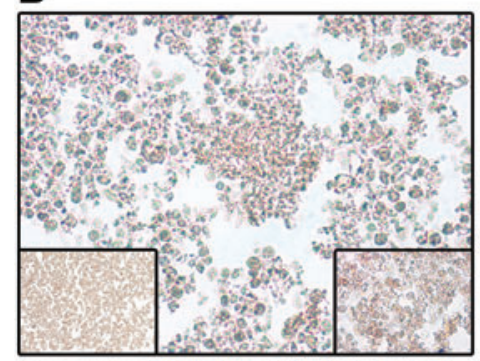

C

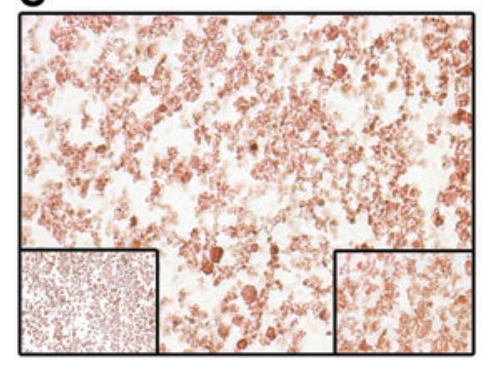

rAAV-hIGF-I
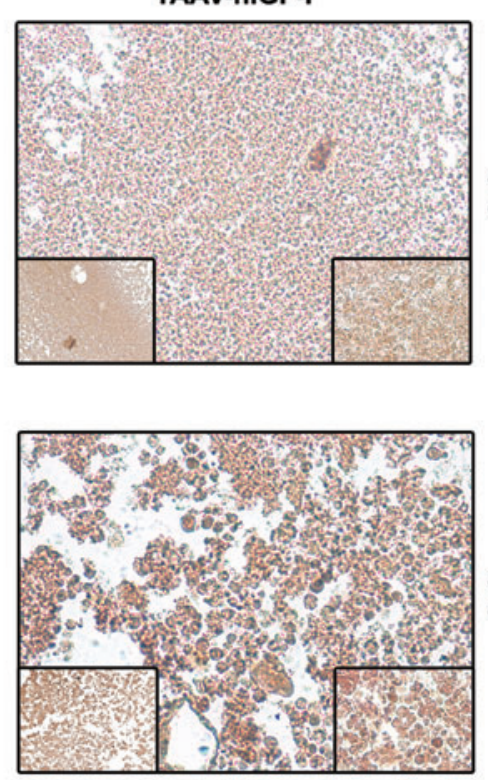

\section{anti-type-X} collagen

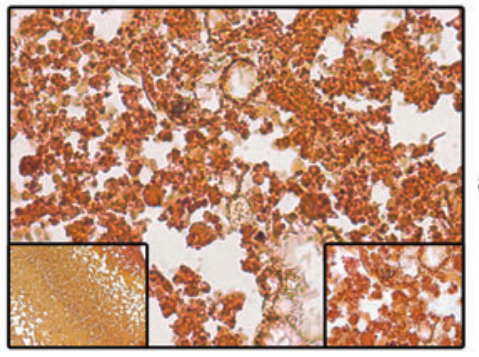

alizarin red
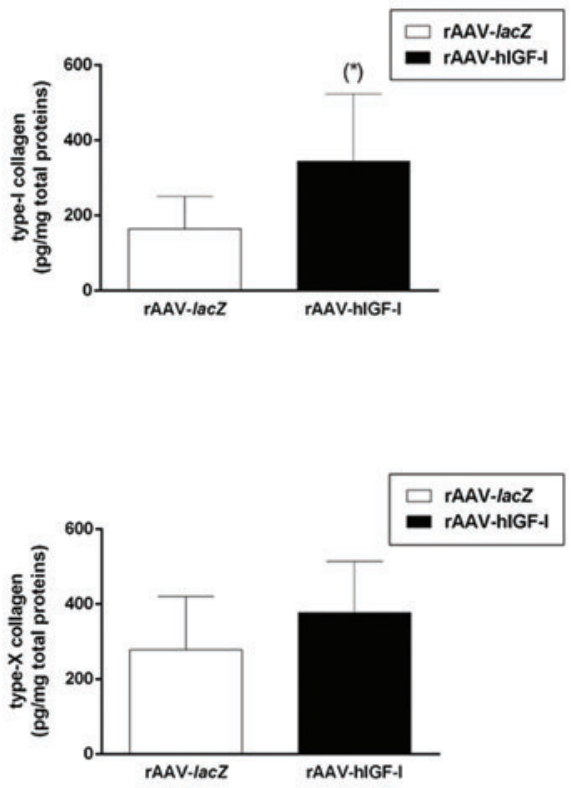

FIG. 4. Hypertrophic and terminal differentiation processes in human bone marrow aspirates transduced with rAAVhIGF-I. Aspirates were transduced and maintained in chondrogenic medium as described in Figure 1 and histologically processed after 21 days to monitor the levels and production of type-I (A) and type-X collagen, (B) (immunodetection and estimation of the contents), and (C) of matrix mineralization (Alizarin red staining) (magnification $\times 40$, insets left at magnification $\times 20$, insets right at magnification $\times 100$, representative data). ${ }^{*}$ Statistically significant compared with $\mathrm{rAAV}$ lacZ. Color images available online at www.liebertpub.com/tea 

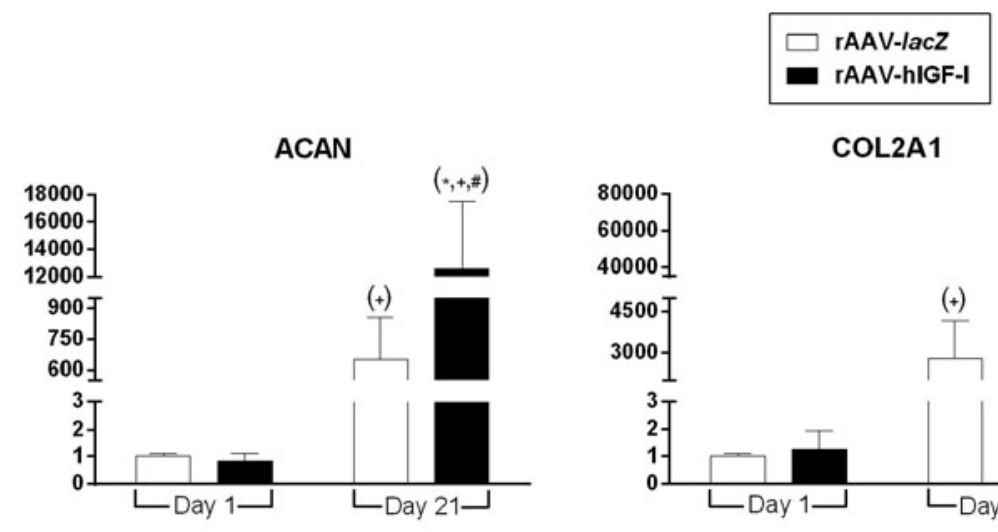

COL2A1
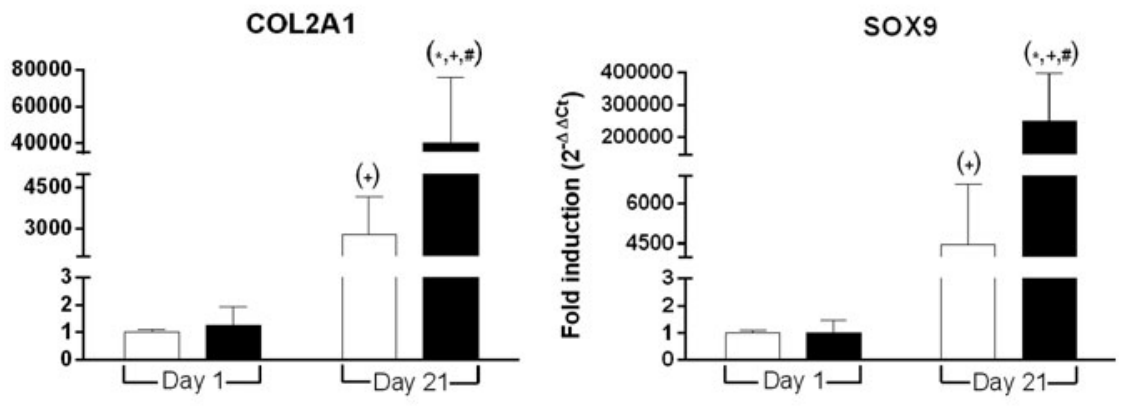

COL1A1

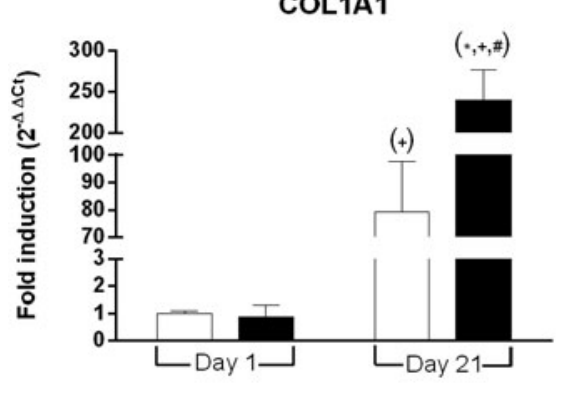

COL10A1
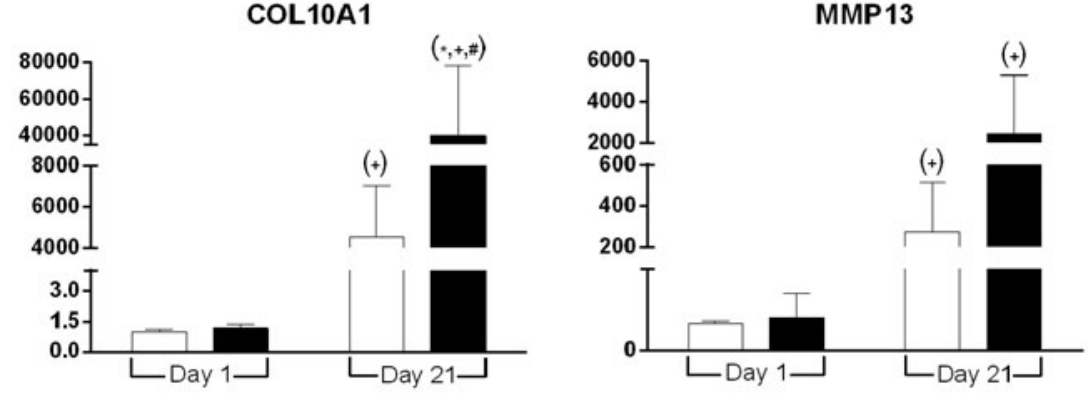

ALP
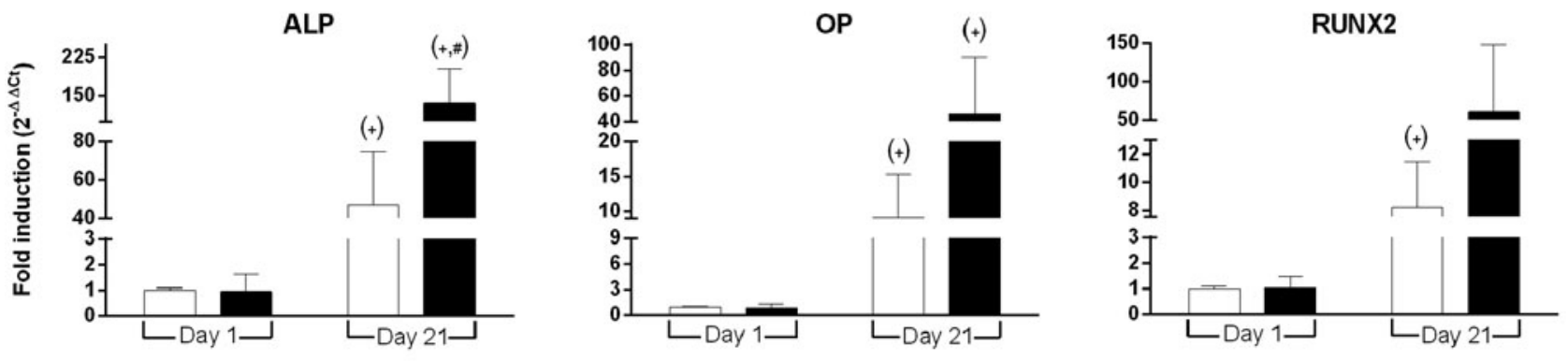

$\beta$-catenin

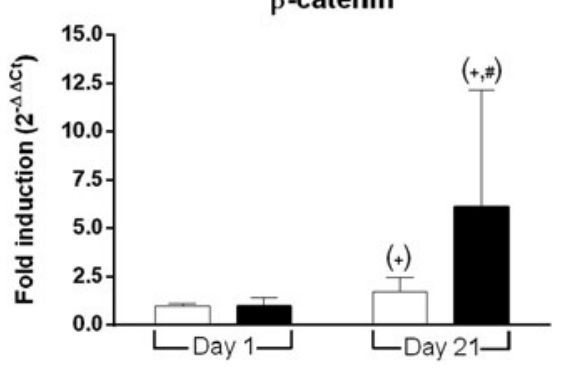

IHH

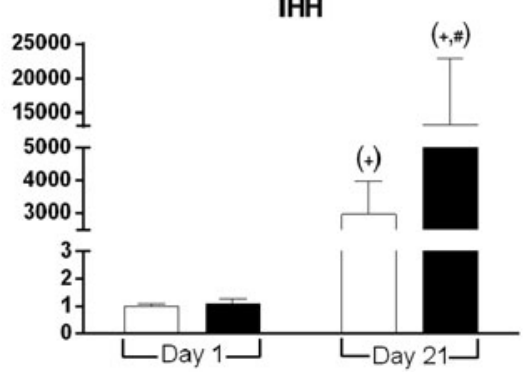

PTHrP

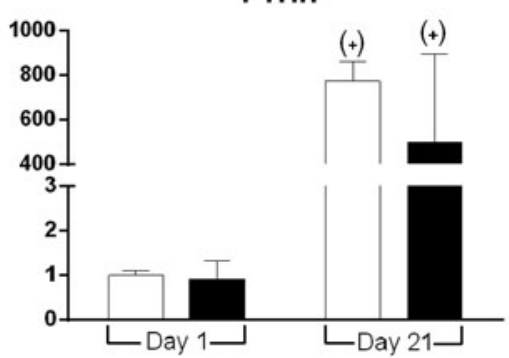

FIG. 5. Expression analyses through real-time RT-PCR in human bone marrow aspirates transduced with rAAV-hIGF-I. All aspirates were transduced and maintained in chondrogenic medium as described in Figure 1. Total cellular RNA extraction and cDNA synthesis with subsequent analysis of gene expression through real-time reverse transcriptasepolymerase chain reaction (RT-PCR) amplification was performed as described in the Materials and Methods section after 1 and 21 days to generate time course $\mathrm{Ct}$ values for each target. The transcription factor SOX9, type-II collagen (COL2A1), aggrecan (ACAN), type-I collagen (COL1A1), type-X collagen (COL10A1), matrix metalloproteinase 13 (MMP13), ALP, osteopontin (OP), the transcription factor RUNX2, $\beta$-catenin, Indian-hedgehog $(\mathrm{IHH})$, and parathyroid hormone-related protein (PTHrP) were analyzed, with GAPDH serving as a housekeeping gene and internal control for normalization (primers are listed in the Materials and Methods section). Fold inductions were measured for each target at both time points by using the $2^{-\Delta \Delta C t}$ method relative to day $1 \mathrm{rAAV}$-lacZ-treated aspirates. Statistically significant compared with rAAVlac $\mathrm{Z}$ at ${ }^{*}$ corresponding or ${ }^{+}$earlier time point and with ${ }^{*}$ rAAV-hIGF-I at earlier time point. 
$p \leq 0.001$; COL10A1: 4533- and 34,055-fold with lacZ and IGF-I, respectively, i.e., 7.5-fold more with IGF-I, $p \leq 0.014$ ) (Fig. 5). Finally, treatment with IGF-I for 21 days enhanced the levels of these markers in the aspirates compared with samples treated with lacZ for 1 day (240- and 40,017-fold for COL1A1 and COL10A1, respectively, $p \leq 0.001$ ) (Fig. 5).

Trends toward increases in the expression of MMP13 (8.9-fold, $p=0.225)$, ALP (2.9-fold, $p=0.126)$, OP (5.1fold, $p=0.065)$, RUNX2 (7.4-fold, $p=0.100), \quad \beta$-catenin (3.6-fold, $p=0.222$ ), and IHH (4.4-fold, $p=0.202$ ) were noted when IGF-I was applied for 21 days to the aspirates under chondrogenic induction relative to lacZ at a similar time point (Fig. 5). An evaluation of the outcomes at day 21 versus day 1 per vector type revealed over time increases in the expression of these markers in both types of aspirates (MMP13: 276- and 2016-fold with lacZ and IGF-I, respectively, i.e., 7.3-fold more with IGF-I, $p=0.007$ and $p=0.060$; ALP: 47- and 142-fold with lacZ and IGF-I, respectively, i.e., three-fold more with IGF-I, $p \leq 0.005$; OP: 9- and 50-fold with lacZ and IGF-I, respectively, i.e., 5.6fold more with IGF-I, $p \leq 0.014$ and $p=0.072$; RUNX2: 8and 59-fold with $l a c Z$ and IGF-I, respectively, i.e., 7.4-fold more with IGF-I, $p \leq 0.001$ and $p=0.212 ; \beta$-catenin: 2 - and 6-fold with $l a c Z$ and IGF-I, respectively, i.e., 3-fold more with IGF-I, $p \leq 0.037$; IHH: 2982- and 11,881-fold with lacZ and IGF-I, respectively, i.e., 4-fold more with IGF-I, $p \leq 0.017$ ) (Fig. 5). Finally, treatment with IGF-I for 21 days enhanced the expression levels of these markers in the aspirates compared with samples treated with lac $Z$ for 1 day (2453-, 135-, 46-, 6-, and 13,207-fold for MMP13, ALP, OP, $\beta$-catenin, and $\mathrm{IHH}$, respectively, $p \leq 0.021$ ) (Fig. 5). Of further note, a trend towards decrease in the PTHrP expression was observed in the aspirates treated under chondrogenic induction with IGF-I for 21 days relative to $l a c Z$ at a similar time point (1.5-fold, $p=0.137$ ) (Fig. 5). An over time increase in the PTHrP expression was seen in both types of aspirates at day 21 versus day 1 when comparing

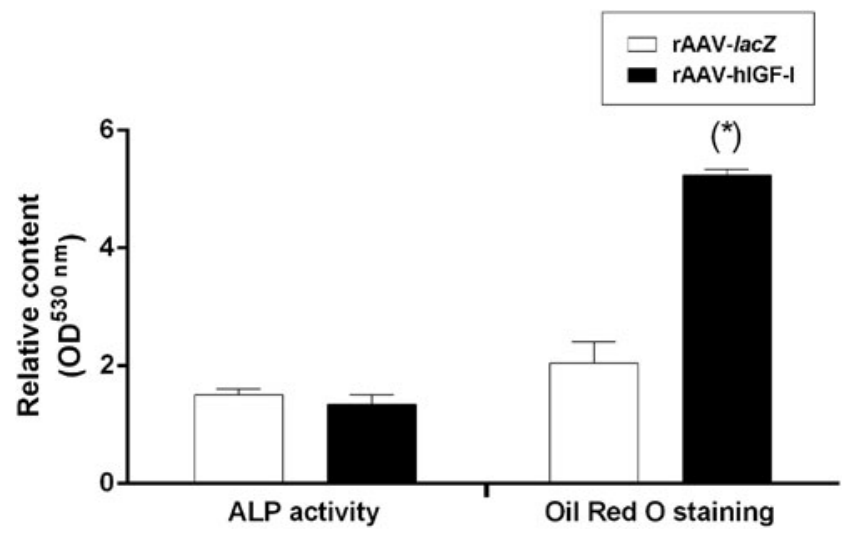

FIG. 6. Osteogenic and adipogenic differentiation processes in human bone marrow aspirates transduced with rAAV-hIGFI. Aspirates were transduced with rAAV-hIGF-I or rAAV-lacZ ( $40 \mu \mathrm{L}$ each vector), kept in either osteogenic or adipogenic medium, and processed after 21 days to quantitatively estimate the alkaline phosphatase (ALP) activities (osteogenesis) and Oil Red O staining (adipogenesis) in the samples, respectively, by spectrophotometry (OD ${ }^{530 \mathrm{~nm}}$ ) as described in the Materials and Methods section. similar vector condition (772- and 550-fold with $l a c Z$ and IGF-I, respectively, i.e., 1.4-fold more with lacZ, $p \leq 0.001$ and $p=0.082$ ) and treatment with IGF-I for 21 days enhanced the levels of this marker compared with samples modified by lacZ for 1 day (499-fold, $p=0.007$ ) (Fig. 5).

\section{Effects of $r A A V$-hIGF-I on the osteogenic and adipogenic differentiation processes in human bone marrow aspirates}

Finally, bone marrow aspirates were transduced in either osteogenic or adipogenic conditions to evaluate possible effects of IGF-I overexpression through rAAV upon these differentiation processes compared with control (lacZ) treatment. In the conditions applied here, administration of the rAAV IGF-I vector did not significantly modify the ALP activities in the aspirates compared with the lac $Z$ condition ( $p=1.000)$, possibly due to differences of sensitivity of the detection methods with the real-time RT-PCR analysis, while overexpression of the candidate factor significantly increased the levels of Oil Red O staining (2.6-fold, $p=0.019$ ) (Fig. 6).

\section{Discussion}

Application of marrow concentrates as a practical, singlestep approach to treat articular cartilage lesions is clinical reality to provide options that are less complex and invasive than those based on the implantation of isolated progenitor cells, ${ }^{10,11,43}$ but the quality of the repair tissue generated with such treatments still remains inferior to that of the original hyaline cartilage. This issue might be addressed by genetically modifying the concentrates to improve their chondroregenerative capabilities. ${ }^{5}$ In the present study, we focused on delivering a sequence coding for the mitogenic and proanabolic IGF-I factor through potent and clinically adapted rAAV vectors to human marrow concentrates with respect to our previous findings showing that this construct was capable of enhancing the proliferative, biosynthetic, and chondrogenic activities of isolated human MSCs in vitro. ${ }^{20}$

Our results first demonstrate that high levels of cells expressing the IGF-I transgene were achieved in marrow aspirates $(\sim 80 \%)$, concordant with findings based on the previous use of reporter (lacZ) rAAV vectors. ${ }^{36}$ For comparison, other groups ${ }^{34,35}$ reported that administration of adenoviral vectors to rabbit and sheep aspirates led to the modification of an important number of cells, but using much higher vector doses $\left(10^{10}\right.$ adenoviral particles per $250 \mu \mathrm{L}$ of aspirate versus $8 \times 10^{5}$ rAAV particles per $100 \mu \mathrm{L}$ here, i.e., a 5.000-fold difference). We next show that application of rAAV-hIGF-I significantly increased the levels of IGF-I production in the concentrates compared with control (lacZ) treatment over the whole period of evaluation (21 days), in good agreement with our previous results when applying this vector to isolated hMSCs. ${ }^{20}$ Also of note, the levels of IGF-I produced in the aspirates upon rAAV-hIGF-I gene transfer were in the range of those reached in isolated hMSCs using the same construct (up to $105.9 \pm 35.1 \mathrm{pg}$ $\mathrm{rhIGF}-\mathrm{I} / \mathrm{mg}$ total proteins in the aspirates, i.e., $1.3 \pm 0.5 \mathrm{ng} /$ $\mathrm{mL}$ at an $\mathrm{MOI}=10 \pm 3$ compared with up to $2.9 \pm 0.4 \mathrm{ng} / \mathrm{mL}$ in cells with an $\mathrm{MOI}=20) .{ }^{20}$ While early on all cell types present in the aspirates (MSCs, hematopoietic cells, fibroblasts) may be subjected to $\mathrm{AAV}$-mediated gene transfer, at extended periods of time under continuous chondrogenic 
stimulation, only MSCs capable of competently committing toward the chondrocyte phenotype in such an environment ${ }^{13-15}$ might become the prevalent source of therapeutic factor overexpression. Still, the other cells in the aspirates may remain viable over the time of culture and influence the biological outcomes.

The present data further indicate that IGF-I overexpression through rAAV significantly enhanced the proliferative, biosynthetic, and chondrogenic activities in the aspirates over time, compared with control treatment, and at late versus early time points, possibly due to the sustained levels of growth factor achieved with this class of persistent vector ${ }^{44}$ and consistent with the properties of IGF-I ${ }^{39,45}$ and with our previous work in isolated hMSCs. ${ }^{20}$ The levels of proliferation achieved here in the aspirates upon rAAV-hIGF-I gene transfer were higher than those reached in isolated hMSCs using the same construct $(\sim 2.5 \mu \mathrm{g}$ DNA/mg total proteins versus $\sim 9 \mathrm{ng} / \mathrm{mg}$ total proteins, respectively, i.e., a 271 -fold difference),${ }^{20}$ probably due to the presence of other mitogenic factors in the aspirates and/or to possible paracrine effects of other marrow cell types modified early on by rAAV in the aspirates as reported using different experimental conditions in adherent cell cultures, ${ }^{46}$ while later on, under continuous chondrogenic activation mostly the chondrogenically induced, rAAV-transduced MSCs may contribute to this process. Interestingly, even though the biosynthetic and chondrogenic activities were stimulated in the IGF-I- versus lacZ-treated aspirates, the levels of matrix synthesis activated by overexpression of IGF-I were inferior to those observed using isolated hMSCs $(\sim 40 \mu \mathrm{g}$ proteoglycans/mg total proteins versus $\sim 284 \mu \mathrm{g} / \mathrm{mg}$ total proteins, respectively, and $\sim 350 \mathrm{pg}$ type-II collagen/mg total proteins versus $\sim 13 \mu \mathrm{g} /$ $\mathrm{mg}$ total proteins, respectively, i.e., 7 - to $3.7 \times 10^{4}$-fold difference). ${ }^{20}$ These observations may reflect a lower state of activation of chondroprogenitor cells in the aspirates compared with that acquired upon expansion in culture, potential adverse effects played by other residual cells still present in the aspirate over the time of culture, or to prevalent mitogenic versus anabolic effects of IGF-I in the aspirates as seen in articular chondrocytes ${ }^{39}$ (as supported by the findings on the type-II collagen contents showing only trend towards changes). Also, the outcomes may be the result of a particular timing of matrix synthesis in marrow aspirates, with production of a matrix at 21 day (a time point selected based on previous work for approaches aiming at cartilage repair ${ }^{34,35}$ and as previously reported ${ }^{39}$ ) that may be fully deposited later on (between 40 and 50 days). ${ }^{47,48}$

We finally show that modification of the concentrates by rAAV-hIGF-I transduction led to increases in the expression of hypertrophic and osteogenic markers, an effect possibly associated with enhanced levels of MMP13 (marker of terminal differentiation), ALP and OP (osteogenic markers), RUNX2 (transcription factor controlling the osteoblastic expression of COL1, COL10, and MMP13), $\beta$-catenin (mediator of the Wnt pathway for osteogenic differentiation), and IHH (hypertrophy-associated marker), and to the decrease in PTHrP expression (antihypertrophic factor) mediated by the overexpression of IGF-I, although only trends were generally noted, again possibly due to a matter of timing (partial effects at day 21 vs. possible completion by days 40-50), ${ }^{4,48}$ but nevertheless concordant with the previous findings ${ }^{49}$ and with our observations in isolated
hMSCs. ${ }^{20}$ Similarly, production of IGF-I promoted a significant activation of adipogenic differentiation in the aspirates, also in good agreement with previous work from other groups and with our findings in isolated hMSCs. ${ }^{20,50}$

In conclusion, the results of the present study validate the concept of applying rAAV vectors to human bone marrow concentrates as a means to stimulate the chondrogenic differentiation processes and offer convenient, effective tools for cartilage repair upon IGF-I overexpression, provided that a precise regulation of the levels of IGF-I produced by such modification is afforded before reimplantation in cartilage lesions to prevent premature terminal differentiation and ossification in vivo. ${ }^{34,35,51-53}$ This might be achieved by using tissue-specific or regulatable promoters or by coadministrating vectors coding for factors that are known to prevent or delay such undesirable effects (FGF-2; SOX5/SOX6/SOX9 transcription factors; PTHrP; siRNA, shRNA, or miRNA sequences targeting coll or Runx2/Cbfa-1). ${ }^{19,22-25,32,36,54,55}$ Again, rAAV might be the best-suited gene vehicles to provide combinations of vectors and genes in marrow concentrates as no interference in transduction and transgene expression has been reported so far when delivering separate constructs from this class of vector. ${ }^{56,57}$ Future work will be needed to adjust the timing of matrix deposition to achieve full chondrogenesis in the aspirates, for instance by performing longer time course evaluations. Such an approach might also provide insights into a possible influence of residual, other cell types upon the biological outcomes in the aspirate cultures over time. In addition, directing the initially quiescent MSCs within the aspirates to form a functional cartilaginous tissue will be necessary, an issue that might be again addressed by using MSC-specific promoters (SOX9 or type-II collagen regulatory elements instead of the CMV-IE promoter). An alternative option would be to induce first the aspirates under chondrogenic conditions, and next provide the candidate vectors. Equally important, work is ongoing to thoroughly characterize the cell subpopulations expressing the rAAV transgenes in the aspirates ${ }^{58}$ and explore the prevalence of the specific effects mediated by the genetically modified MSCs over all other marrow cell types, ${ }^{13-15,58}$ and to address the cell heterogeneity of the aspirates (like by using cell-specific promoters in the vectors to specifically target chondroprogenitor cells). The potential benefits of the present approach are also under investigation in vivo using clinically relevant models of orthotopic focal cartilage defect that provide a natural joint microenvironment for innate chondrogenesis. $^{34,35,51-53}$ compared with less-suited ectopic models (subcutaneous transplantation in SCID mouse lacking all joint tissues participating in the repair processes) as a means to corroborate the present findings in human marrow aspirates. The possible use of such a procedure for cartilage repair in vivo is supported by findings showing the formation of cartilage-like tissue in focal lesions following implantation of aspirates modified through adenoviral gene transfer. ${ }^{34,35}$ Overall, our findings show the feasibility of directly modifying marrow concentrates through rAAV as a potential approach to improve articular cartilage repair.

\section{Acknowledgments}

This research was funded by grants from the German Osteoarthritis Foundation (Deutsche Arthrose-Hilfe e.V.) 
and the Collaborative Research Partner Acute Cartilage Injury Program of AO Foundation (Davos, Switzerland). The authors thank R.J. Samulski (The Gene Therapy Center, University of North Carolina, Chapel Hill, NC), X. Xiao (The Gene Therapy Center, University of Pittsburgh, Pittsburgh, PA), and E.F. Terwilliger (Division of Experimental Medicine, Harvard Institutes of Medicine and Beth Israel Deaconess Medical Center, Boston, MA) for providing genomic AAV-2 plasmid clones and the 293 cell line, and A.J. D'Ercole and B. Moats-Staats (Department of Pediatrics, University of North Carolina, Chapel Hill) for the human IGF-I cDNA.

\section{Disclosure Statement}

No competing financial interests exist.

\section{References}

1. Buckwalter, J.A. Articular cartilage: injuries and potential for healing. J Orthop Sports Phys Ther 28, 192, 1998.

2. Brittberg, M., Lindahl, A., Nilsson, A., Ohlsson, C., Isaksson, O., and Peterson, L. Treatment of deep cartilage defects in the knee with autologous chondrocyte transplantation. N Engl J Med 331, 889, 1994.

3. Horas, U., Pelinkovic, D., Herr, G., Aigner, T., and Schnettler, R. Autologous chondrocyte implantation and osteochondral cylinder transplantation in cartilage repair of the knee joint. A prospective, comparative trial. J Bone Joint Surg Am 85-A, 185, 2003.

4. Knutsen, G., Engebretsen, L., Ludvigsen, T.C., Drogset, J.O., Grontvedt, T., Solheim, E., Strand, T., Roberts, S., Isaksen, V., and Johansen, O. Autologous chondrocyte implantation compared with microfracture in the knee. A randomized trial. J Bone Joint Surg Am 86-A, 455, 2004.

5. Orth, P., Rey-Rico, A., Venkatesan, J.K., Madry, H., and Cucchiarini, M. Current perspectives in stem cell research for knee cartilage repair. Stem Cells Cloning 7, 1, 2014.

6. Dewan, A.K., Gibson, M.A., Elisseeff, J.H., and Trice, M.E. Evolution of autologous chondrocyte repair and comparison to other cartilage repair techniques. Biomed Res Int 2014, 272481, 2014.

7. Tibesku, C.O., Szuwart, T., Kleffner, T.O., Schlegel, P.M., Jahn, U.R., Van Aken, H., and Fuchs, S. Hyaline cartilage degenerates after autologous osteochondral transplantation. J Orthop Res 22, 1210, 2004.

8. Orozco, L., Munar, A., Soler, R., Alberca, M., Soler, F., Huguet, M., Sentis, J., Sanchez, A., and Garcia-Sancho, J. Treatment of knee osteoarthritis with autologous mesenchymal stem cells: a pilot study. Transplantation 95, 1535, 2013.

9. Wakitani, S., Mitsuoka, T., Nakamura, N., Toritsuka, Y., Nakamura, Y., and Horibe, S. Autologous bone marrow stromal cell transplantation for repair of full-thickness articular cartilage defects in human patellae: two case reports. Cell Transplant 13, 595, 2004.

10. Gigante, A., Cecconi, S., Calcagno, S., Busilacchi, A., and Enea, D. Arthroscopic knee cartilage repair with covered microfracture and bone marrow concentrate. Arthrosc Tech 1, e175, 2012.

11. Kim, J.D., Lee, G.W., Jung, G.H., Kim, C.K., Kim, T., Park, J.H., Cha, S.S., and You, Y.B. Clinical outcome of autologous bone marrow aspirates concentrate (BMAC) injection in degenerative arthritis of the knee. Eur J Orthop Surg Traumatol 24, 1505, 2014.
12. Slynarski, K., Deszczynski, J., and Karpinski, J. Fresh bone marrow and periosteum transplantation for cartilage defects of the knee. Transplant Proc 38, 318, 2006.

13. Anam, K., and Davis, T.A. Comparative analysis of gene transcripts for cell signaling receptors in bone marrowderived hematopoietic stem/progenitor cell and mesenchymal stromal cell populations. Stem Cell Res Ther 4, 112, 2013.

14. Lennon, D.P., Haynesworth, S.E., Arm, D.M., Baber, M.A., and Caplan, A.I. Dilution of human mesenchymal stem cells with dermal fibroblasts and the effects on in vitro and in vivo osteochondrogenesis. Dev Dyn 219, 50, 2000.

15. Shapiro, F., Koide, S., and Glimcher, M.J. Cell origin and differentiation in the repair of full-thickness defects of articular cartilage. J Bone Joint Surg Am 75, 532, 1993.

16. Frisch, J., Venkatesan, J.K., Rey-Rico, A., Madry, H., and Cucchiarini, M. Current progress in stem cell-based gene therapy for articular cartilage repair. Curr Stem Cell Res Ther 10, 121, 2015.

17. Babister, J.C., Tare, R.S., Green, D.W., Inglis, S., Mann, S., and Oreffo, R.O. Genetic manipulation of human mesenchymal progenitors to promote chondrogenesis using "beadin-bead" polysaccharide capsules. Biomaterials 29, 58, 2008.

18. Bocker, W., Yin, Z., Drosse, I., Haasters, F., Rossmann, O., Wierer, M., Popov, C., Locher, M., Mutschler, W., Docheva, D., and Schieker, M. Introducing a single-cell-derived human mesenchymal stem cell line expressing hTERT after lentiviral gene transfer. J Cell Mol Med 12, 1347, 2008.

19. Cucchiarini, M., Ekici, M., Schetting, S., Kohn, D., and Madry, H. Metabolic activities and chondrogenic differentiation of human mesenchymal stem cells following recombinant adeno-associated virus-mediated gene transfer and overexpression of fibroblast growth factor 2. Tissue Eng Part A 17, 1921, 2011.

20. Frisch, J., Venkatesan, J.K., Rey-Rico, A., Schmitt, G., Madry, H., and Cucchiarini, M. Influence of insulin-like growth factor I overexpression via recombinant adeno-associated vector gene transfer upon the biological activities and differentiation potential of human bone marrow-derived mesenchymal stem cells. Stem Cell Res Ther 5, 103, 2014.

21. Haleem-Smith, H., Calderon, R., Song, Y., Tuan, R.S., and Chen, F.H. Cartilage oligomeric matrix protein enhances matrix assembly during chondrogenesis of human mesenchymal stem cells. J Cell Biochem 113, 1245, 2012.

22. Huang, J., Zhao, L., Xing, L., and Chen, D. MicroRNA-204 regulates Runx2 protein expression and mesenchymal progenitor cell differentiation. Stem Cells 28, 357, 2010.

23. Ikeda, T., Kamekura, S., Mabuchi, A., Kou, I., Seki, S., Takato, T., Nakamura, K., Kawaguchi, H., Ikegawa, S., and Chung, U.I. The combination of SOX5, SOX6, and SOX9 (the SOX trio) provides signals sufficient for induction of permanent cartilage. Arthritis Rheum 50, 3561, 2004.

24. Jeon, S.Y., Park, J.S., Yang, H.N., Woo, D.G., and Park, K.H. Co-delivery of SOX9 genes and anti-Cbfa-1 siRNA coated onto PLGA nanoparticles for chondrogenesis of human MSCs. Biomaterials 33, 4413, 2012.

25. Kim, H.J., and Im, G.I. Electroporation-mediated transfer of SOX trio genes (SOX-5, SOX-6, and SOX-9) to enhance the chondrogenesis of mesenchymal stem cells. Stem Cells Dev 20, 2103, 2011.

26. Kim, J.H., Park, J.S., Yang, H.N., Woo, D.G., Jeon, S.Y., Do, H.J., Lim, H.Y., Kim, J.M., and Park, K.H. The use of biodegradable PLGA nanoparticles to mediate SOX9 gene delivery in human mesenchymal stem cells (hMSCs) and induce chondrogenesis. Biomaterials 32, 268, 2011. 
27. Liu, T.M., Guo, X.M., Tan, H.S., Hui, J.H., Lim, B., and Lee, E.H. Zinc-finger protein 145, acting as an upstream regulator of $\mathrm{SOX} 9$, improves the differentiation potential of human mesenchymal stem cells for cartilage regeneration and repair. Arthritis Rheum 63, 2711, 2011.

28. Liu, T.M., Ng, W.M., Tan, H.S., Vinitha, D., Yang, Z., Fan, J.B., Zou, Y., Hui, J.H., Lee, E.H., and Lim, B. Molecular basis of immortalization of human mesenchymal stem cells by combination of p53 knockdown and human telomerase reverse transcriptase overexpression. Stem Cells Dev 22, 268, 2013.

29. Neumann, A.J., Alini, M., Archer, C.W., and Stoddart, M.J. Chondrogenesis of human bone marrow-derived mesenchymal stem cells is modulated by complex mechanical stimulation and adenoviral-mediated overexpression of bone morphogenetic protein 2. Tissue Eng Part A 19, 1285, 2013.

30. Pagnotto, M.R., Wang, Z., Karpie, J.C., Ferretti, M., Xiao, X., and Chu, C.R. Adeno-associated viral gene transfer of transforming growth factor-betal to human mesenchymal stem cells improves cartilage repair. Gene Ther 14, 804, 2007.

31. Steinert, A.F., Weissenberger, M., Kunz, M., Gilbert, F., Ghivizzani, S.C., Gobel, S., Jakob, F., Noth, U., and Rudert, M. Indian hedgehog gene transfer is a chondrogenic inducer of human mesenchymal stem cells. Arthritis Res Ther 14, R168, 2012.

32. Venkatesan, J.K., Ekici, M., Madry, H., Schmitt, G., Kohn, D., and Cucchiarini, M. SOX9 gene transfer via safe, stable, replication-defective recombinant adeno-associated virus vectors as a novel, powerful tool to enhance the chondrogenic potential of human mesenchymal stem cells. Stem Cell Res Ther 3, 22, 2012.

33. Yang, H.N., Park, J.S., Woo, D.G., Jeon, S.Y., Do, H.J., Lim, H.Y., Kim, S.W., Kim, J.H., and Park, K.H. Chondrogenesis of mesenchymal stem cells and dedifferentiated chondrocytes by transfection with SOX Trio genes. Biomaterials 32, 7695, 2011.

34. Pascher, A., Palmer, G.D., Steinert, A., Oligino, T., Gouze, E., Gouze, J.N., Betz, O., Spector, M., Robbins, P.D., Evans, C.H., and Ghivizzani, S.C. Gene delivery to cartilage defects using coagulated bone marrow aspirate. Gene Ther 11, 133, 2004.

35. Ivkovic, A., Pascher, A., Hudetz, D., Maticic, D., Jelic, M., Dickinson, S., Loparic, M., Haspl, M., Windhager, R., and Pecina, M. Articular cartilage repair by genetically modified bone marrow aspirate in sheep. Gene Ther 17, 779, 2010.

36. Rey-Rico, A., Frisch, J., Venkatesan, J.K., Schmitt, G., Madry, H., and Cucchiarini, M. Determination of effective rAAV-mediated gene transfer conditions to support chondrogenic differentiation processes in human primary bone marrow aspirates. Gene Ther 22, 50, 2015.

37. Samulski, R.J., Chang, L.S., and Shenk, T. A recombinant plasmid from which an infectious adeno-associated virus genome can be excised in vitro and its use to study viral replication. J Virol 61, 3096, 1987.

38. Samulski, R.J., Chang, L.S., and Shenk, T. Helper-free stocks of recombinant adeno-associated viruses: normal integration does not require viral gene expression. J Virol 63, 3822, 1989.

39. Weimer, A., Madry, H., Venkatesan, J.K., Schmitt, G., Frisch, J., Wezel, A., Jung, J., Kohn, D., Terwilliger, E.F., Trippel, S.B., and Cucchiarini, M. Benefits of recombinant adeno-associated virus (rAAV)-mediated insulinlike growth factor I (IGF-I) overexpression for the long-term recon- struction of human osteoarthritic cartilage by modulation of the IGF-I axis. Mol Med 18, 346, 2012.

40. Baker, N., Zhang, G., You, Y., and Tuan, R.S. Caveolin-1 regulates proliferation and osteogenic differentiation of human mesenchymal stem cells. J Cell Biochem 113, 3773, 2012.

41. Baksh, D., Yao, R., and Tuan, R.S. Comparison of proliferative and multilineage differentiation potential of human mesenchymal stem cells derived from umbilical cord and bone marrow. Stem Cells 25, 1384, 2007.

42. Martella, E., Bellotti, C., Dozza, B., Perrone, S., Donati, D., and Lucarelli, E. Secreted adiponectin as a marker to evaluate in vitro the adipogenic differentiation of human mesenchymal stromal cells. Cytotherapy 16, 1476, 2014.

43. Gorski, A., Kniotek, M., Perkowska-Ptasinska, A., Mroz, A., Przerwa, A., Gorczyca, W., Dabrowska, K., WeberDabrowska, B., and Nowaczyk, M. Bacteriophages and transplantation tolerance. Transplant Proc 38, 331, 2006.

44. Xiao, X., Li, J., and Samulski, R.J. Efficient long-term gene transfer into muscle tissue of immunocompetent mice by adeno-associated virus vector. J Virol 70, 8098, 1996.

45. Osborn, K.D., Trippel, S.B., and Mankin, H.J. Growth factor stimulation of adult articular cartilage. J Orthop Res 7, 35, 1989.

46. Ahmed, N., Vogel, B., Rohde, E., Strunk, D., Grifka, J., Schulz, M.B., and Grassel, S. CD45-positive cells of haematopoietic origin enhance chondrogenic marker gene expression in rat marrow stromal cells. Int J Mol Med 18, 233, 2006.

47. Cavallo, C., Desando, G., Columbaro, M., Ferrari, A., Zini, N., Facchini, A., and Grigolo, B. Chondrogenic differentiation of bone marrow concentrate grown onto a hylauronan scaffold: rationale for its use in the treatment of cartilage lesions. J Biomed Mater Res A 101, 1559, 2013.

48. Grigolo, B., Cavallo, C., Desando, G., Manferdini, C., Lisignoli, G., Ferrari, A., Zini, N., and Facchini, A. Novel nano-composite biomimetic biomaterial allows chondrogenic and osteogenic differentiation of bone marrow concentrate derived cells. J Mater Sci Mater Med 26, 173, 2015.

49. Koch, H., Jadlowiec, J.A., and Campbell, P.G. Insulin-like growth factor-I induces early osteoblast gene expression in human mesenchymal stem cells. Stem Cells Dev 14, 621, 2005.

50. Scavo, L.M., Karas, M., Murray, M., and Leroith, D. Insulin-like growth factor-I stimulates both cell growth and lipogenesis during differentiation of human mesenchymal stem cells into adipocytes. J Clin Endocrinol Metab 89, 3543, 2004.

51. Cucchiarini, M., and Madry, H. Overexpression of human IGF-I via direct rAAV-mediated gene transfer improves the early repair of articular cartilage defects in vivo. Gene Ther 21, 811, 2014.

52. Cucchiarini, M., Madry, H., Ma, C., Thurn, T., Zurakowski, D., Menger, M.D., Kohn, D., Trippel, S.B., and Terwilliger, E.F. Improved tissue repair in articular cartilage defects in vivo by rAAV-mediated overexpression of human fibroblast growth factor 2. Mol Ther 12, 229, 2005.

53. Cucchiarini, M., Orth, P., and Madry, H. Direct rAAV SOX9 administration for durable articular cartilage repair with delayed terminal differentiation and hypertrophy in vivo. J Mol Med (Berl) 91, 625, 2013.

54. Fischer, J., Aulmann, A., Dexheimer, V., Grossner, T., and Richter, W. Intermittent PTHrP(1-34) exposure augments chondrogenesis and reduces hypertrophy of mesenchymal stromal cells. Stem Cells Dev 23, 2513, 2014. 
55. Zhang, F., Yao, Y., Zhou, R., Su, K., Citra, F., and Wang, D.A. Optimal construction and delivery of dual-functioning lentiviral vectors for type I collagen-suppressed chondrogenesis in synovium-derived mesenchymal stem cells. Pharm Res 28, 1338, 2011.

56. Cucchiarini, M., Terwilliger, E.F., Kohn, D., and Madry, H. Remodelling of human osteoarthritic cartilage by FGF-2, alone or combined with Sox9 via rAAV gene transfer. J Cell Mol Med 13, 2476, 2009.

57. Rendahl, K.G., Leff, S.E., Otten, G.R., Spratt, S.K., Bohl, D., Van Roey, M., Donahue, B.A., Cohen, L.K., Mandel, R.J., Danos, O., and Snyder, R.O. Regulation of gene expression in vivo following transduction by two separate rAAV vectors. Nat Biotechnol 16, 757, 1998.

58. Jones, E.A., Kinsey, S.E., English, A., Jones, R.A., Straszynski, L., Meredith, D.M., Markham, A.F., Jack, A.,
Emery, P., and McGonagle, D. Isolation and characterization of bone marrow multipotential mesenchymal progenitor cells. Arthritis Rheum 46, 3349, 2002.

Address correspondence to: Magali Cucchiarini, PhD Center of Experimental Orthopaedics Saarland University Medical Center Kirrbergerstr. Bldg 37 D-66421 Homburg/Saar

Germany

E-mail: mmcucchiarini@hotmail.com

Received: December 9, 2014 Accepted: June 26, 2015

Online Publication Date: July 21, 2015 